\title{
ENVIRONMENTAL SUSTAINABILITY AND QUALITY OF LIFE: FROM THEORY TO PRACTICE
}

\author{
I.G. MALKINA-PYKH \& Y.A. PYKH \\ Research Center for Interdisciplinary Environmental Cooperation of Russian Academy of Sciences \\ (INENCO RAS), Saint-Petersburg, Russia.
}

\begin{abstract}
The term Quality of Life (QoL) has been widely used in a number of disciplines to express the idea of personal well-being in a framework, which goes beyond the simple economic equation of well-being (SWB) with income. The results of numerous studies reveal that (1) objective well-being may be compatible with environmental sustainability, often due to synergies arising in terms of reduced pollution and health benefits; (2) well-being and environmental sustainability may be incompatible with one another if well-being is defined as the satisfaction of preferences, psychological well-being and/or subjective well-being (SWB). One possible way of better constructing both concepts of environmental sustainability and well-being is by linking them to individual mental maps (models). Mental maps are those core beliefs that may explain how individuals select and process information in interpreting life events, and may account for individual differences in these interpretations. We argue that the prerequisite and basic mechanism for both environmental sustainability and well-being is the mental sustainability of these internal working models. We define mental sustainability an optimal balance between social adaptability and individual authenticity of a person. The current study is the first stage of the interdisciplinary project focusing on clarifying approaches to, and relationships between, subjective well-being and environmental sustainability. The aim of this study is to apply our operationalisation of SWB for investigating what personality factors are responsible for consumerism (consumption satisfaction). Our results revealed that people with significantly different levels of consumption satisfaction also had significantly different levels of SWB as well as of all other personality variables under consideration.

Keywords: environmental sustainability, personality variables, quality of life, subjective well-being.
\end{abstract}

\section{INTRODUCTION}

Environmental sustainability is a key issue for human societies throughout the 21st century's world. Goals of sustainable development can be expressed in either a weaker, steady state formulation or in a stronger more utopian formulation, making the world a better place. Within the concern for the environment, steady-state sustainability encompasses the most well used definition of the concept that comes from the Brundtland report (1987) where sustainable development requires that we leave enough resources for future generations to satisfy their needs [1].

However, as human populations continue to grow, material consumption intensifies and production technology further expands; by consequence the quantity and quality of environmental resources keep steadily decreasing [2]. The Happy Planet Index (HPI) created by the New Economics Foundation [3] to answer such questions as, 'does happiness have to cost the earth?' indicates that many of the wealthiest countries are exerting extensive pressure on natural resources and consuming more than their fair share of resources [4]. Several reports 
28 Environmental and Economic Impact on Sustainable Development

identified consumption at the crux of the relationship between environmental sustainability and well-being [5-7].

\subsection{Quality-of-life: definitions and domains}

The term Quality of Life (QoL) is a broad concept and has been widely used in a number of disciplines to express the idea of personal well-being in a framework, which goes beyond the simple economic equation of well-being (SWB) with income [8]. QoL encompasses both objective factors (e.g. command of material resources, health, work status, living conditions and many others) and the subjective well-being (SWB). The judgement about what objective things are needed for quality-of-life (education, health etc.) does not come from the individual but draws on theoretical and intuitive accounts of what is of value [9].

There are two main theoretical traditions that have contributed to the understanding of SWB [10]. A 'bottom up' perspective mainly analyzed the impact of contextual factors in the SWB of individuals that was explained by a linear combination of domain-specific satisfaction (DS) variables, such as satisfaction with income, housing, or social contacts. Diener [11] was the first who suggested that the effects could just as well be reversed, that is, go from SWB to DS. He called his model the 'top-down' model in contrast to the 'bottom-up' model. This suggestion was based on the idea that satisfaction might be determined more by personality characteristics, such as temperament, social comparison, the goal-achievement gap and adaptation, than situational circumstances.

\subsection{Environmental sustainability and well-being: synergies and tensions}

The results of numerous studies reveal that (1) objective well-being may be compatible with environmental sustainability, often due to synergies arising in terms of reduced pollution and health benefits; (2) well-being and environmental sustainability may be incompatible with one another if well-being is defined as the psychological well-being, and/or SWB [12].

For averting the threat of environmental resource depletion, a variety of approaches toward changing user behaviours have been proposed, such as providing technical alternatives, regulatory rules, financial incentives, information, social examples, and/or organizational change [2]. However, the studies revealed that external incentives needed constant reintroduction to remain effective and they proved to be less reliable than we had hoped. Thus, the evidence suggests that policies that act upon objective circumstances may not have the desired effect unless values, perceptions, expectation and attitudes are considered. Whilst it is known that positive attitudes towards the environment often underlie environmentalism, how these attitudes develop is less well understood. Attempts to understand the psychological factors contributing to consumerism and environmentalism have largely focused on the role of values, beliefs and personal norms [13].

\subsection{Consumerism (materialism), personality and SWB}

Consumerism has been conceptualized as a value structure that emphasizes the importance of material possessions and the pursuit of personal wealth [14]. Several studies investigated the associations between materialism and stable personality traits [15]. The Big Five personality traits (namely Extraversion, Agreeableness, Conscientiousness, Neuroticism, and Openness) emerged as significant predictors of Consumerism [16]. Specifically, Agreeableness 
negatively predicted Consumerism. These findings can be interpreted as specific instances of the higher-order trait-value relationships found in the literature. In particular, Agreeableness and Openness are negatively related to the higher-order value of self-enhancement [17].

Another distinct characteristic of materialistic values is that they appear to be negatively related to SWB $[18,19]$. However, the nature of this relationship has generated considerable controversy. Some studies show that income contributes to SWB, even after controlling for all the benefits of earnings [18]. Contrary to that, other studies showed that materialism has a detrimental effect on well-being and that people striving for financial success have diminished QoL [20]. Deci and Ryan's [21] self-determination theory of motivation assumes that persons who view money and wealth as central values are likely to be both more control oriented and less psychologically integrated. The results of three longitudinal studies [20] present consistent findings that support the possibility that decreasing one's focus on materialistic aims is associated with improvements in one's psychological well-being over time. Different theoretical perspectives suggest that diverse kinds of threats can make people shift towards extrinsic goals and away from intrinsic goals [22]. People who strive for money and goods might suffer from underlying feeling of insecurity [23].

Thus, we hypothesize that it is possible that unhappiness motivate people to focus on material wealth. A related explanation may also be applied: individuals dispositionally high on broad factors such as neuroticism, perfectionism or low self-esteem, may be more prone to view money as a means of self-enhancement.

\subsection{Environmentalism, personality and SWB}

In recognition of the fact that human behaviour has a large influence on the global environment many researchers have investigated the social and psychological factors that influence environmental attitudes and behaviours. Much of this research has focused on the role of specific values, beliefs and norms as predictors of environmental concern [13].

Also, environmentalism has been examined from the perspective of the Big Five taxonomies of personality traits. Two of these traits, Agreeableness and Openness, have emerged as significant predictors of pro-environmental values [16]. Another study extends this previous research by examining the personality predictors of environmental concern in a much larger community sample of German adults [24]. As in previous research, greater environmental concern was related to higher levels of the Big Five personality traits of Agreeableness and Openness [16].

The purported conflict between human happiness and planetary welfare is countered by a small body of research findings suggesting that SWB and ecologically responsible behaviour (ERB) may be compatible pursuits. For example, [25] found that environmental and prosocial behaviours (including frugality and community participation) provide intrinsic satisfactions that bolster personal well-being.

The model of relations between sustainable behaviour and SWB tested in the study [26] revealed a significant association between these two psychological factors. According to these results, it might be assumed that the more pro-ecological, altruistic, frugal and equitable a person is, the more her/his feeling of happiness (s) he experiences. Some results reveal that happier people are living in more ecologically sustainable ways; well-being positively influences sustainable acting [27].

Overall, the current findings emphasize the importance of personality in predicting consumerism and environmentalism. While social and structural factors undoubtedly influence 
30 Environmental and Economic Impact on Sustainable Development

both of these domains, examining the contributions of individual personality traits also appears to be a fruitful approach.

\subsection{The origin of SWB, consumerism, environmentalism}

Both bottom-up and top-down theoretical approaches, however, ignore the cardinal question of how personality influences SWB. The top-down theory does not explain how and why predispositional reactions to stimuli influence SWB, while the bottom-up theoretical approach does not explain how different people can experience the same events but have very different interpretations. One possible way of better constructing both concepts of environmental sustainability and well-being is by linking them to individual mental maps (models). Mental maps are those core beliefs that may explain how individuals select and process information in interpreting life events, and may account for individual differences in these interpretations.

Recent findings in neuroscience and developmental psychology propose some possible explanations of the sources of these thought processes (mental models). Attachment theory explains how parents and other environmental impact 'programmed' the child without conscious discrimination because highly suggestible state of subconsciousness dominated by the emotional brain (right hemisphere) characterizes the child development during the first years of life [28].

We argue that the prerequisite and basic mechanism for both environmentally sustainable behaviour and well-being is the mental sustainability of these internal working models. We define the mental sustainability as an optimal balance (intrinsic balance) between social adaptability and individual authenticity of a person. Social adaptability is a personality trait which shows how a well-connected person is with his/her family, friends and society. Individual authenticity deals with appropriate levels of a person's self-actualization, self-confidence, self-efficacy as well as healthy self-concept and self-esteem. We suggest that mental sustainability may provide an antidote to consumerism.

\subsection{One possible operationalisation of SWB}

In our previous studies, we propose the operationalisation of SWB as a multidimensional variable composed of evaluations about the different domains of satisfaction with life in a bottom-up or component-based approach [29-31]. An advantage of this approach is that judgments on domain satisfaction that are central to determining happiness reflect both subjective factors of the type emphasized in psychology and objective circumstances stressed by economics. Our SWB framework includes five domains (satisfaction with) - material status, health, work, leisure/recreation and personal competence.

Although the Big Five model of personality is the most widely used taxonomy of personality characteristics and certainly provides results about important personality dimensions, it is just as certain that there are other personality characteristics not embodied by the big five that are just as worthy of study (see [29] for review).

In our previous studies the following components of mental model were proposed as predictors of SWB level namely dimensions of self-actualisation (time competence and inner directedness), sociotropy, dimensions of perfectionism (personal standards and concern over mistakes/doubts about actions), general locus of control, body image dissatisfaction, neuroticism, alexithymia [30,31]. These studies presented correlational analysis and linear regression 
model of the relationships between these elements of mental model and SWB. Our findings revealed that SWB was significantly positively $(p<0.01)$ associated with time competence, inner directedness and general locus of control and significantly negatively $(p<0.01)$ with all other psychological variables under study (sociotropy, personal standards, concern over mistakes/doubts about actions, body image dissatisfaction, neuroticism and alexithymia). In the next step we performed a regression analysis using the backward method. SWB variable in the study was introduced as a dependent variable, as independent variables; we introduced all psychological predictors, mentioned above and contextual variables (such as sex and age). The predictors of SWB were sex, time competence, inner-directedness and concern over mistakes/doubts about actions, general locus of control, neuroticism and alexithymia, explaining $66 \%$ of SWB variance.

However, the use of statistical analysis procedures such as correlation analysis, stepwise linear regression, analysis of variance, discriminant analysis or similar statistical techniques based on the general linear model or one of its multivariate generalizations (structural equation models, etc.) prevents us from drawing any conclusions about causality. The problem is that such approaches do not yield information about the linkages between causes and effects, especially in case of nonlinearity of interactions within the system under study. The limitations of such models as exploratory and predictive tools are well known and described elsewhere [32].

\subsection{Generalized multiplicative models of SWB}

Previously, we studied the performance of 'generalized multiplicative models (GMMs)' which are based on the method of response functions and can be used to identify and characterize the nonlinear effect of potential predictors (components of mental map) on the SWB level [29].

GMMs have the form of nonlinear regression models: $F\left(x_{1}, \ldots, x_{n}\right)=\prod_{i=1}^{n} f_{i}\left(\alpha^{i}, x_{i}\right)$, where $x=\left(x_{1}, x_{2}, \ldots, x_{n}\right)$ is a vector of predictors (factors) under consideration, $f_{i}\left(x_{i}\right)$ are partial response functions of each of the factors under study, $F\left(x_{1}, \ldots, x_{n}\right)$ accounts for all the factors considered, is presented as a multiplicative combination of partial response functions $f_{i}\left(x_{i}\right)$ and is defined as generalized response function, $n$ is the number of the factors under study, $\alpha^{i}$ is a vector of parameters, the values of which we have to determine in the process of identification. Basically, it has been criticized that the multiplicative form represents the independence of the influencing factors. Previous studies demonstrated that this problem could be resolved successfully using some specific technique for the evaluation of parameters of the generalized response function $F\left(x_{1}, \ldots, x_{n}\right)$ [29].

Generally speaking, GMMs are accurate models that are interpretable. GMM gives us the possibility to capture as much as possible of cause-effect relationships and describe them with an operator of transition, or "input-output" function. The GMMs describe nonlinear relationships among variables, can handle nominal or ordinal data and does not require multivariate normality. We argue that GMM fills the gap between linear statistical techniques and full complexity models such as psychophysical models, neural modelling, etc.

In our previous study [29] we applied GMM to construct SWB model using the same psychological predictors as in our other studies mentioned above [30, 31]. The main findings of our study [29] indicated that the GMM not only predicts the level of SWB satisfactorily, but also allows obtaining the partial response functions of psychological predictors of SWB 
32 Environmental and Economic Impact on Sustainable Development

directly as a result of model parameters' estimation. The views of the partial response function are corresponding with underlying psychological theories except for variable 'neuroticism'.

The current study is the first stage of the interdisciplinary project focusing on clarifying approaches to, and relationships between, SWB and environmental sustainability. The aim of this study is to apply our operationalisation of SWB for investigating what personality factors are responsible for consumerism (consumption satisfaction).

\section{METHOD}

\subsection{Participants}

The study was conducted in the framework of Mental Health Management Program organised in the 'Human Ecology' department of the Research Center for Interdisciplinary Environmental Cooperation of Russian Academy of Sciences, St-Petersburg, Russia.

At baseline, a total of 182 subjects were recruited among those searching for counselling (psychotherapy) regarding various non-clinical psychological problems: e.g. low self-esteem, family problems, workplace bullying, etc. No any medical disorders or clinical complaints (e.g. diabetes mellitus, rheumatoid arthritis, pulmonary disease, depression, panic attack, etc.) were claimed by the participants. Demographic items included age and gender, which were assessed with single questions. The participants were aged between 18 and 65 years old, mean age was $36.0 \pm 9.8$ years, $36(20 \%)$ were males and $146(80 \%)$ were females.

The study was approved by the Ethics Committee of I.I. Mechnikov North-West State Medical University, St.-Petersburg, Russia, and was performed in accordance with the ethical standards laid down in the 1964 Declaration of Helsinki. All participants signed informed consent form before participating in the study.

\subsection{Measures}

Subjects were assessed with measures listed below. Russian-validated translations of all measures were used.

SWB was measured using the Integral Index of Social Well-being (IISW) [33]. The test includes 20 items based on a three-point Likert scale and covers five domains of SWB: work, material well-being, health, leisure/recreation and personal competence. Examples of IISW items include 'How satisfied are you with your job?' etc. Six questions reflect the Material well-being (satisfaction with the current level of consumption) directly such as 'How satisfied are you with your home, apartment or place where you live?', 'How satisfied are you with your resources to buy fashionable, beautiful clothing?' and one question we add from the Leisure \& Vacation domain: 'How satisfied are you with the length, frequency and quality of vacations you have?' because we argue that it reflects material status indirectly. The responses are tabulated as follows: 1 = 'not satisfied'; 2 = 'don't know (not of interest)'; $3=$ 'satisfied'. Higher scores show the higher levels of SWB, the maximum score is 60.0. The IISW has demonstrated strong internal consistency and test-retest reliability (0.67). In the experimental sample, the IISW items generated alpha coefficients of 0.87 .

Other measures include Time Competence (Tc) and Inner-Directed (I) scales of Personal Orientation Inventory (POI) [34], General Locus of Control Scale of the Locus of Control Inventory (LOC) [35], Neuroticism (N) Scale of the Eysenck Personality Inventory (EPI [36]), 
Toronto Alexithymia Scale-26 (TAS-26) [37], Body Image Test [38], Personal Perfectionism Scale (PPS) of the Multidimensional Perfectionism Scale [39], Sociotropy Scale of Personal Style Inventory (PSI [40]). The detailed descriptions of these measures are available in [29-31].

Participants were given approximately 1 hour to complete the scales described above.

\subsection{Statistical analysis}

Statistical analyses of the obtained data were carried out using SPSS 16.0 for Windows. A one-way ANOVA was used for between-group comparisons.

After assessment all subjects of the experimental group were divided into two groups in accordance with their SWB level: group 1 - (20-40 IISW scores mean very low, low and

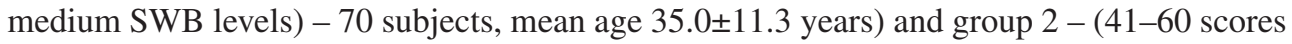
of IISW mean high and very high SWB levels) - 112 subjects, mean age $36.6 \pm 8.6$ years. Two types of ANOVA analyses were provided: with the SWB group as a factor and with gender as a factor.

\section{RESULTS}

Consumption satisfaction was significantly positively associated with overall SWB $(r=0.741, p<0.01)$.

After the groups 1 and 2 were formed, the results of one-way ANOVA with group as a factor in the entire sample indicated no differences in SWB level due to age $(F(1,181)=1.27$,

Table 1: Assessment scores in groups 1 and 2

\begin{tabular}{|c|c|c|c|c|}
\hline $\begin{array}{l}\text { Psychological variables, IISW and } \\
\text { Consumption Satisfaction }\end{array}$ & $\begin{array}{c}\text { Group } 1 \\
\mathrm{~N}=70 \\
\mathrm{M}(\mathrm{SD})\end{array}$ & $\begin{array}{l}\text { Group } 2 \\
\mathrm{~N}=112 \\
\mathrm{M}(\mathrm{SD})\end{array}$ & $\begin{array}{l}\text { ANOVA } \\
F(1,182)\end{array}$ & $\mathrm{p}$ \\
\hline Integral index of social well-being & $38.3(3.6)$ & $49.3(4.4)$ & 286.4 & $<0.001$ \\
\hline Time competence & $6.6(3.1)$ & $8.5(2.7)$ & 17.3 & $<0.001$ \\
\hline Inner-directedness & $40.6(10.0)$ & 49.3(10.4) & 30.8 & $<0.001$ \\
\hline Sociotropy & $93.9(14.2)$ & 81.1(17.3) & 27.4 & $<0.001$ \\
\hline Personal standards & $22.1(5.1)$ & $20.2(5.1)$ & 6.1 & 0.015 \\
\hline Concern over mistakes/doubts about actions & $39.5(9.9)$ & $27.7(8.8)$ & 70.1 & $<0.001$ \\
\hline General locus of control & $4.7(1.9)$ & $5.8(1.8)$ & 16.6 & $<0.001$ \\
\hline Body image dissatisfaction & $22.3(12.2)$ & $15.1(10.4)$ & 18.4 & $<0.001$ \\
\hline Neuroticism & $4.5(4.5)$ & $1.1(4.5)$ & 24.3 & $<0.001$ \\
\hline Alexithymia & $67.9(10.9)$ & $60.3(11.9)$ & 18.8 & $<0.001$ \\
\hline $\begin{array}{l}\text { Satisfaction with the current level of con- } \\
\text { sumption }\end{array}$ & $15.0(2.7)$ & $18.6(2.4)$ & 87.4 & $<0.001$ \\
\hline
\end{tabular}


34 Environmental and Economic Impact on Sustainable Development

$p=0.26)$ or gender $(F(1,181)=2.53, p=0.11)$. The ANOVAs demonstrated that subjects of group 1 compared with the subjects of group 2 have significantly different levels of not only of SWB but of Satisfaction with the current level of consumption as well as of all other personality variables.

The results of ANOVA with gender as a factor didn't indicate any significant differences between males and females in all variables under study ( $p>0.05)$ except for body image dissatisfaction. The scores of this variable in female group are equal 19.4 \pm 11.7 , in male group $-11.3 \pm 9.1, F(1,182)=15.2, p<0.001$.

\section{DISCUSSION AND FUTURE RESEARCH DIRECTIONS}

The findings of our studies reveal that our specific operationalisation of SWB construct has merit. Our research provides evidence that thinking styles (mental models) may indeed play a significant role in influencing SWB in general and consumption satisfaction in particular. This is a role that is not directly accounted for by existing psychological theories of SWB. This particular finding provides a missing link in the bottom-up theory of SWB by partially explaining how personality is linked to SWB and consumerism. The working assumption is that our experience is organized in implicit habituated ways by beliefs rooted in early developmental events.

Future research directions include several themes. First of all we'll use the data on consumption satisfaction and its psychological and contextual predictors for the construction of the GMM model of consumerism.

Second, we'll study the ERBs in the given sample using the General Ecological Behaviour (GEB) measure. It consists of 38 items that assess different types of ecological behaviour (e.g. 'Usually I do not drive my automobile in the city;' 'I put dead batteries in the garbage' (negatively formulated item) and some non-environmental prosaically behaviours (e.g. 'Sometimes I give change to panhandlers'). A yes/no response format for these items is used [41]. The obtained data will be used for the construction of the GMM of environmentalism using the same psychological predictors as in SWB model.

The third area is the interventions for increasing ERB and SWB and evaluation of their effectiveness using GMM. Recent researches suggest that happiness can, to some degree, be changed [42]. In our previous study [43], we applied GMM described above for the prediction of the impact of rhythmic-movement therapy on the subjects' psychological variables resulting in changes of the actual level of SWB. The same psychosocial intervention will be applied for increasing ERB.

\section{REFERENCES}

[1] World Commission on Environment and Development, Our Common Future, Toronto: Oxford University Press, 1987.

[2] Vlek, C. \& Steg, L., Human behavior and environmental sustainability: problemas, driving forces, and research topics. Journal of Social Issues, 63, pp. 1-9, 2007. http://dx.doi.org/10.1111/j.1540-4560.2007.00493.x

[3] Marks, N., Simms, A., Thompson, S. \& Abdallah, S., The Happy Planet Index: an Index of Human Well-being and Environmental Impact, New Economics Foundation and Friends of Earth: London, 2006.

[4] Abdallah, S., Michaelson, J., Shah, S., Stoll, L. \& Marks, N., The Happy Planet Index 2012: A Global Index of Sustainable Well-being, New Economics Foundation and Friends of Earth: London, 2012. 
[5] Sachs, J., Chapter 1 Introduction. In World Happiness Report, eds. J.F. Helliwell, R. Layard \& J. Sachs, The Earth Institute, Columbia University: New York, pp. 2-9, 2012. http://dx.doi.org/10.1007/978-3-8349-6942-2_1

[6] Reeves, R., The Politics of Happiness: A NEF Discussion Paper (London: New Economics Foundation), 2003.

[7] Kasser, T., Materialism and its alternatives. In A Life Worth Living: Contributions to Positive Psychology, M. Csikszentmi-halyi \& I. Csikszentmihalyi, Toronto: Oxford University Press, pp. 200-214, 2006.

[8] Malkina-Pykh, I.G. \& Pykh, Y.A., Quality-of-life indicators at different scales: theoretical background. Ecological Indicators, 8, pp. 854-862, 2008.

[9] Dolan, P., Peasgood, T. \& White, M., Review of research on the influences on personal well-being and application to policy making. Report prepared for the UK's Department of Environment, Food and Rural Affairs (DEFRA), 2006.

[10] Diener, E., Suh, E.M., Lucas, R.E. \& Smith, H.L., Subjective well-being: Three decades of progress. Psychological Bulletin, 125, pp. 276-302, 1999.

http://dx.doi.org/10.1037/0033-2909.125.2.276

[11] Diener, E., Subjective well-being. Psychological Bulletin, 95, pp. 542-575, 1984. http://dx.doi.org/10.1037/0033-2909.95.3.542

[12] Phillips, D., Quality of life and sustainability. International Journal of Environmental, Cultural, Economic and Social Sustainability, 2(2), pp. 103-112, 2006.

[13] Dietz, T., Fitzgerald, A. \& Shwom, R., Environmental values. Annual Review of Environment and Resources, 30, pp. 335-372, 2005. http://dx.doi.org/10.1146/annurev.energy.30.050504.144444

[14] Fournier, S. \& Richins, M.L., Some theoretical and popular notions concerning materialism. Journal of Social Behavior and Personality, 6, pp. 403-414, 1991.

[15] Roberts, B.W., O’Donnell, M. \& Robins, R.W., Goal and personality trait development in emerging adulthood. Journal of Personality and Social Psychology, 87, pp. 541-550, 2004. http://dx.doi.org/10.1037/0022-3514.87.4.541

[16] Hirsh, J.B. \& Dolderman, D., Personality predictors of consumerism and environmentalism: a preliminary study. Personality and Individual Differences, 43, pp. 1583-1593, 2007. http://dx.doi.org/10.1016/j.paid.2007.04.015

[17] Oliver, J.M. \& Mooradian, T.A., Personality traits and personal values: a conceptual and empirical investigation. Personality and Individual Differences, 35, pp. 109-125, 2003. http://dx.doi.org/10.1016/S0191-8869(02)00145-9

[18] Diener, E. \& Biswas-Diener, R., Will money increase subjective well-being? Social Indicators Research, 57, pp. 119-169, 2002. http://dx.doi.org/10.1023/A:1014411319119

[19] Kasser, T. \& Ahuvia, A., Materialistic values and well-being in business students. European Journal of Social Psychology, 32, pp. 137-146, 2001. http://dx.doi.org/10.1002/ejsp.85

[20] Kasser, N., Rosenblum, K.L., Sameroff, A.J., Deci, E.L., Niemiec, C.P., Ryan, R.M. et al. Changes in materialism, changes in psychological well-being: Evidence from three longitudinal studies and an intervention experiment. Motivation and Emotion, 38, pp. 1-22, 2014. http://dx.doi.org/10.1007/s11031-013-9371-4 
36 Environmental and Economic Impact on Sustainable Development

[21] Deci, E.L. \& Ryan, R.M., Intrinsic Motivation and Self-Determination in Human Behavior, Plenum Press: New York, 1985. http://dx.doi.org/10.1007/978-1-4899-2271-7

[22] Buss, D.M., The evolution of happiness. American Psychologist, 55, pp. 15-23, 2000. http://dx.doi.org/10.1037/0003-066X.55.1.15

[23] Kasser, T. \& Sheldon, K.M., On wealth and death: materialism, mortality salience and consumption behavior. Psychological Science, 11(4), pp. 348-351, 2000. http://dx.doi.org/10.1111/1467-9280.00269

[24] Hirsh, J.B., Personality and environmental concern. Journal of Environmental Psychology, 30, pp. 245-248, 2010. doi:10.1016/j.jenvp.2010.01.004 http://dx.doi.org/10.1016/j.jenvp.2010.01.004

[25] De Young, R., Expanding and evaluating motives for environmentally responsible behavior. Journal of Social Issues, 56(3), pp. 509-526, 2000. http://dx.doi.org/10.1111/0022-4537.00181

[26] Corral-Verdugo, V., Mireles-Acosta, J., Tapia-Fonllem, C. \& Fraijo-Sing, B., Happiness as correlate of sustainable behavior: a study of pro-ecological, frugal, equitable and altruistic actions that promote subjective wellbeing. Human Ecology Review, 18(2), pp. 95-104, 2011.

[27] Brown, K.W. \& Kasser, T., Are psychological and ecological well-being compatible? the role of values, mindfulness, and lifestyle. Social Indicators Research, 74, pp. 349-368, 2005. http://dx.doi.org/10.1007/s11205-004-8207-8

[28] Schore, A.N., The neurobiology of attachment and early personality organization. Journal of Prenatal and Perinatal Psychology and Health, 16(3), pp. 249-263, 2002.

[29] Malkina-Pykh, I.G. \& Pykh, Y.A., The Method of Response Function in Psychology and Sociology, Southampton Boston: WIT Press, p. 245, 2013.

[30] Malkina-Pykh, I.G., Psychological correlates of subjective well-being in the Russian sample. Modern Studies of Russian Society: A Collective Monograph. - Helsinki: Unigrafia. pp. 185-199, 2014.

[31] Malkina-Pykh, I.G., Effectiveness of rhythmic movement therapy: case study of subjective well-being. Body, Movement and Dance in Psychotherapy: An International Journal for Theory, Research and Practice, 10(2), pp. 106-120, 2015. http://dx.doi.org/10.1080/17432979.2014.977822

[32] Seber, G.A.F. \& Wild, C.J., Nonlinear Regression, NewYork: JohnWiley, 1989. http://dx.doi.org/10.1002/0471725315

[33] Panina, N. \& Golovakha, E., Tendencies in the Development of Ukrainian Society (1994-1998), Sociological Indicators. Kyiv: Institute of Sociology, 2001.

[34] Shostrom, E., Personal Orientation Inventory: Manual, San Diego: Edits, 1974.

[35] Rean, A.A., Handbook of Personality Assessment, Saint-Petersburg: Saint-Petersburg University Press, 2001.

[36] Eysenck, H.J. \& Eysenck, S.B.G., Manual of the Eysenck Personality Inventory, University of London Press: London, 1963.

[37] Taylor, G.J., Ryan, D.P. \& Bagby, R.M., Oward the development of a new self-report alexithymia scale. Psychotherapy and Psychosomatics, 44, pp. 191-199, 1985. http://dx.doi.org/10.1159/000287912

[38] Jade, D. Body Image Test. In Therapy of Eating Bahaviour, I.G. Malkina-Pykh, EKSMO: Moscow, pp. 347-349, 2007. 
[39] Frost, R.O., Marten, P., Lahart, C. \& Rosenblate, R., The dimensions of perfectionism. Cognitive Therapy and Research, 14, pp. 449-468, 1990. http://dx.doi.org/10.1007/BF01172967

[40] Robins, C.J., Ladd, J., Welkowitz, J., Blaney, P.H., Diaz, R. \& Kutcher, G., The personal style inventory: preliminary validation studies of new measures of sociotropy and autonomy. Journal of Psychopathology and Behavior Assessment, 16, pp. 277-300, 1994.

http://dx.doi.org/10.1007/BF02239408

[41] Kaiser, F., A general measure of ecological behavior. Journal of Applied Social Psychology, 28, pp. 395-442, 1998. http://dx.doi.org/10.1111/j.1559-1816.1998.tb01712.x

[42] Lyubomirsky, S., Practicing gratitude and positive thinking. The How of Happiness: A Scientific Approach to Getting the Life you Want, New York: Penguin Press, 2007.

[43] Malkina-Pykh, I.G., Predicting and increasing subjective well-being: response function model and rhythmic movement therapy. arXiv: 1507.01891, 2015.

http://dx.doi.org/ 10.13140/2.1.4118.0968 